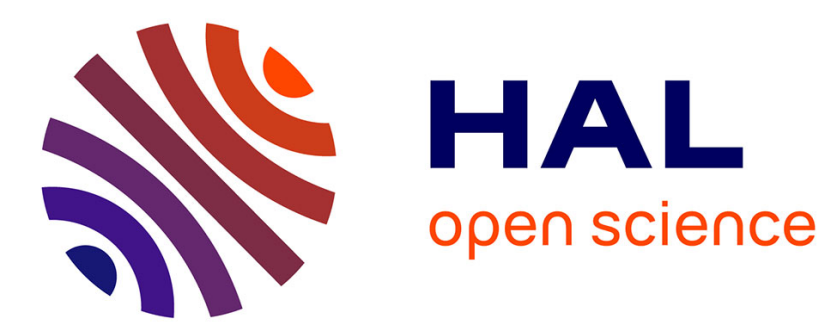

\title{
Distance Teaching of Organic Chemistry Tutorials During the COVID-19 Pandemic: Focus on the Use of Videos and Social Media
}

Pierre-Edouard Danjou

\section{- To cite this version:}

Pierre-Edouard Danjou. Distance Teaching of Organic Chemistry Tutorials During the COVID-19 Pandemic: Focus on the Use of Videos and Social Media. Journal of Chemical Education, 2020, 97 (9), pp.3168-3171. 10.1021/acs.jchemed.0c00485 . hal-02904272

\section{HAL Id: hal-02904272 \\ https://hal.science/hal-02904272}

Submitted on 20 Jan 2022

HAL is a multi-disciplinary open access archive for the deposit and dissemination of scientific research documents, whether they are published or not. The documents may come from teaching and research institutions in France or abroad, or from public or private research centers.
L'archive ouverte pluridisciplinaire HAL, est destinée au dépôt et à la diffusion de documents scientifiques de niveau recherche, publiés ou non, émanant des établissements d'enseignement et de recherche français ou étrangers, des laboratoires publics ou privés. 


\section{Distance teaching of organic chemistry tutorials during the COVID-19 pandemic: focus on the use of videos and social-media}

Pierre-Edouard Danjou ${ }^{a, b, *}$

5

a Département de Chimie, Université du Littoral Côte d'Opale, 220 Avenue de l'université, Dunkerque, France

b Unité de Chimie Environnementale et Interactions sur le Vivant, EA 4492, Université du Littoral Côte d'Opale, 145 Avenue Maurice Schumann, MREI 1, Dunkerque, France

ABSTRACT

The distance teaching of organic chemistry to first-year undergraduate students during lockdown represents a challenge for both students and teachers. To face this challenge, a method combining synchronous and asynchronous teaching was presented in this paper. The asynchronous part of the teaching was achieved through the broadcast of videos on the social network Facebook in order to allow each student to progress at his or her own pace. The synchronous part of the teaching was carried out thanks to the Discord platform in order to answer students' questions live (written and oral) as well as to keep a social link with them. The videos have been recorded at home with the minimum of material and the equipment is reported. To assess the efficiency of this alternative teaching compared to distance real-time teaching during disruption, a questionnaire completed by students was used and discussed. 


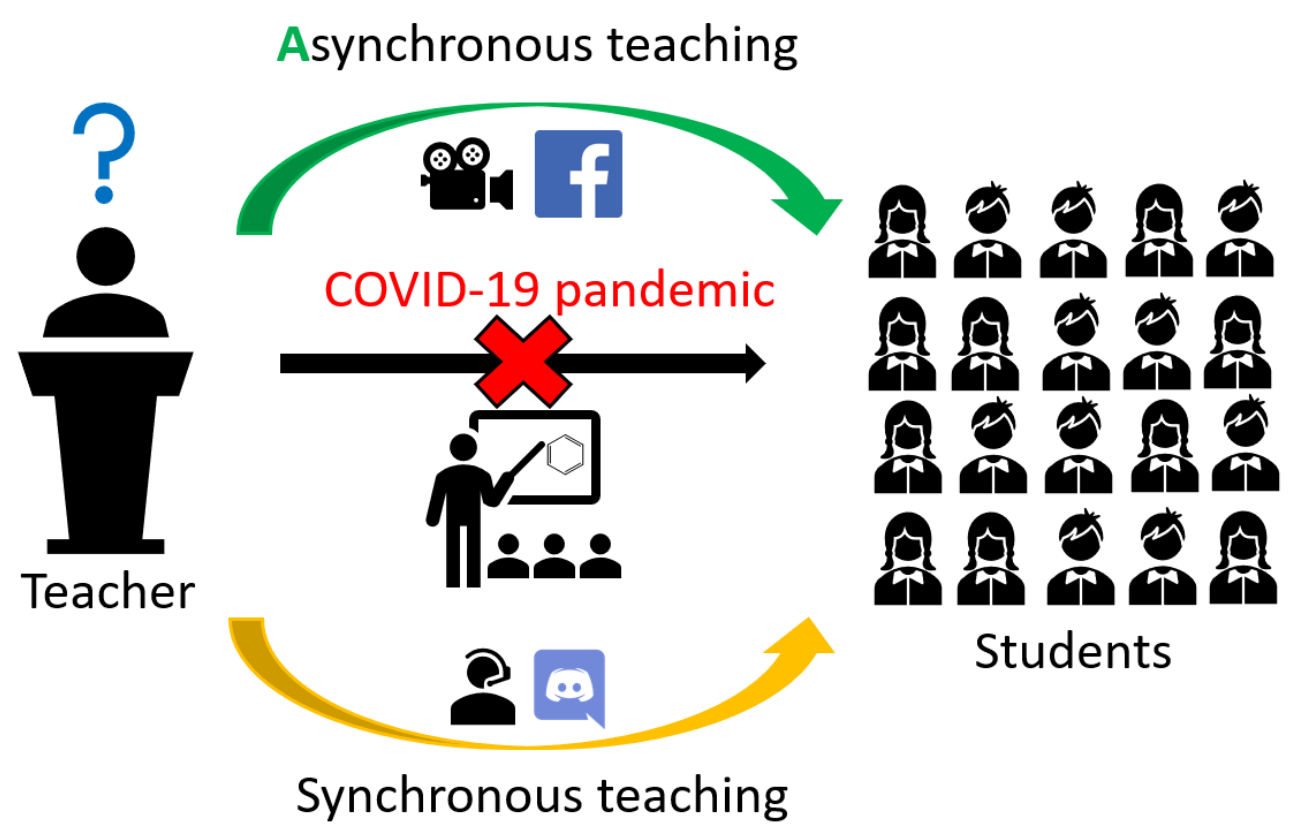

\section{KEYWORDS}

25 First-Year Undergraduate / Organic Chemistry / Distance Learning / Web-Based Learning

\section{INTRODUCTION}

Like all French universities, and many others around the world, the Universite du Littoral Côte d'Opale (ULCO, France) had to stop hosting its students due to the COVID-19 pandemic. The closure of the institution, announced on Friday 13 March 2020 and taking effect on the following Monday, was brutal for both research and teaching activities. Nevertheless, the teaching community had to ensure pedagogical continuity in order to provide its students with the knowledge necessary for their success.

Faced with this unprecedented event, the teaching community had to be imaginative and adaptive in order to continue its activity. ULCO's chemistry department quickly chose to gather its students and teachers within the free platform Discord ${ }^{1}$ mainly used by the online video game community. This platform, recommended by some students, allows to gather students and teachers in private voice or text chat rooms in order to continue education. It also allows the live sharing of a screen display with up to 50 participants. This way of teaching is reminiscent of traditional classes with a teacher facing 
his students in a classroom. This model may seem reassuring, however, it has limitations, particularly in terms of computer equipment shared within a family and slow internet connection on working hours. Any courses that the student has not been able to attend cannot be easily made up. In addition, Discord does not allow hosting video content. The use of the social network Facebook makes it possible to overcome these limitations by hosting video content that is accessible $24 / 7$. While the concept of inverted classes ${ }^{2,3,4}$ based on the use of digital resources for the transmission of knowledge at home followed by classroom problem solving supervised by a teacher has become widespread in the teaching community, it is interesting to recall the words of N. J. Pienta in an editorial² in this Journal: "To be successful, both instructors and students must be prepared". We were not prepared. Moreover, in the flipped environment, tutorials are supposed to take place in the presence of the teacher, which is not possible at the time of lockdown due to the COVID-19 pandemic. So, this paper will detail an experience of teaching organic chemistry tutorials to a small class of first-year undergraduate students in physics and chemistry during the lockdown. The lectures were fully conducted prior to the lockdown and only the tutorials had to be conducted remotely. The first-year organic chemistry curricula include classical topics like nomenclature, structure of molecules, electronic effects, aromaticity, isomerism and finally stereoisomerism.

\section{TEACHING APPROACH}

After considering the implications of the closure of the university, it was quickly necessary to imagine how organic chemistry teaching could be continued, taking into account the following constraints:

60 - Organic chemistry is a living chemistry that requires the drawing (usually by hand) of molecules, electron movements, vectors, etc. A good understanding of many notions requires a correct writing of organic structures. The provision of "static" solutions in PDF does not seem to be an appropriate choice.

- Students may have technical and personal constraints that prevent them during this period of lockdown from being present at a given time or from following a live course correctly (shared internet network and computer equipment, lack of a quiet and isolated room to work in, 
proximity to the family, load within the family, medical appointments, etc.). It therefore appears necessary to keep synchronous teaching to a minimum.

- Faced with the overload of networks and internet servers related to distance learning (and teleworking), it is important to choose a stable, robust and universally accessible platform (preferably free of charge) in order to gather first-year students. The chosen platform should be able to support a large number of simultaneous connections and the easy upload of documents (pdf, videos).

- Confined to the home, access to the university's resources in terms of interactive rooms, videoconferencing room and video recording equipment is impossible for the teachers. The teaching solution must therefore be as basic as possible and do not involve inaccessible equipment.

- Teachers may have young children and a spouse who is also teleworking, so it is necessary that this new way of teaching to be compatible with a family confinement. Facebook) has emerged as a relevant option for maximizing student engagement in this disrupted learning period. ${ }^{6}$ In addition, the use of a social network should allow for mutual support among students. ${ }^{7}$ In order to help students to study, this asynchronous mode of teaching was coupled with synchronous session on the Discord platform in order to be able to exchange live with the students while they work on the exercises, and also to reassure them that they were not alone in these troubled times and that the pedagogical team was doing its utmost for their success. Once this choice had been made, it was necessary to find the simplest and cheapest way to record videos because access to specific equipment (graphics tablet, camera, interactive room, lightboard ${ }^{8}$ etc.) is not possible at home.

\section{EQUIPMENT}

The video recording device (Figure 1) is intended to be extremely simple and accessible to all teachers, both in terms of its operation and the equipment required. It consists of a smartphone capable of recording video content placed on top of a sheet of paper that acts as a whiteboard thanks to a rigid, transversal support (wooden slat, plexiglass sheet, etc.). This rigid support can stand on 
boxes or stacks of books of approx. $25 \mathrm{~cm}$ in height depending on the focal length of the smartphone. Thus, to explain the solutions of the exercises or to remind students of course notions that they have not mastered properly, one needs to launch the video acquisition and start talking while having the possibility to draw molecules on the paper as one could do on a blackboard in the classroom. This solution, close to the Khan-style video format, 9 has the advantage of not using a graphics tablet or any other expensive and potentially inaccessible accessory during the lockdown.

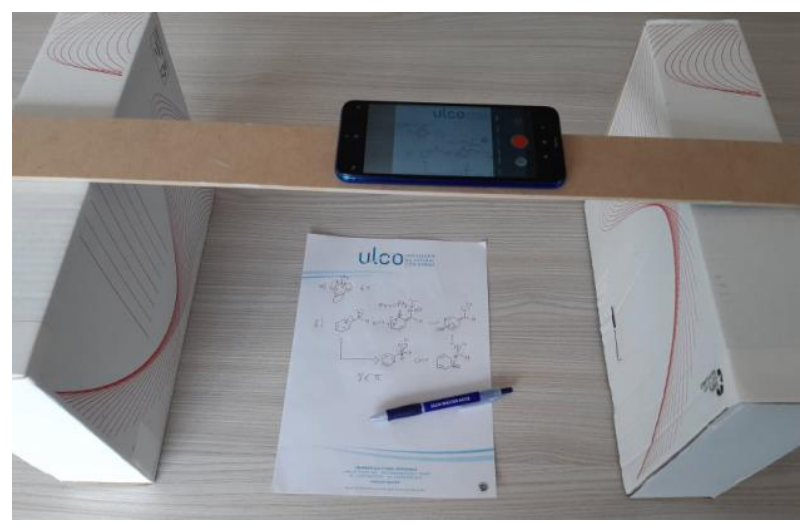

\section{Figure 1 : Photograph of the video recording equipment}

\section{TEACHING METHOD}

This device allowed the recording of about 50 videos for more than 5 cumulated hours. Among these 5 hours, the reminders on the notions seen in the lectures (at the request of the students) represent 45 minutes divided into 7 videos (hybridization, dipolar moment, mesomerism, representation of Newmann and cyclohexane conformation). The videos have been uploaded on Facebook (Figure 2) and students are invited to watch them and ask questions (via Facebook or Discord) if a notion remains confused. 


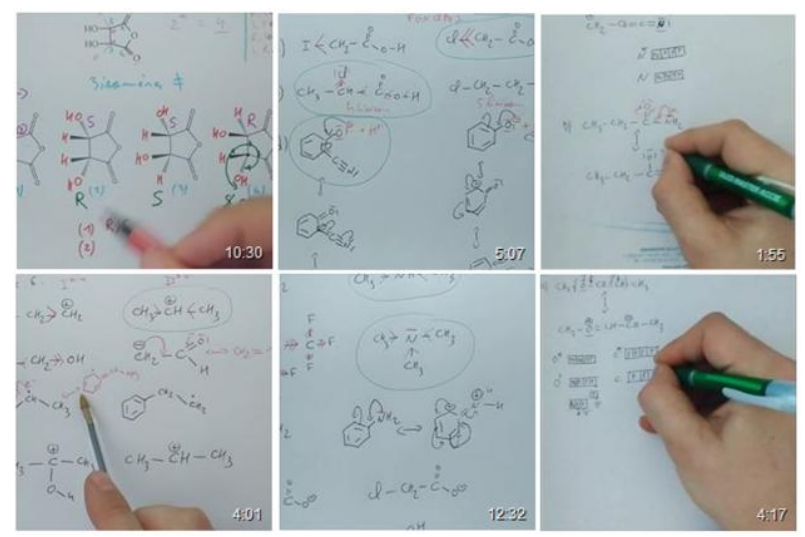

\section{Figure 2 : Illustration of video thumbnails visible on Facebook}

It should be noted that, contrary to what was expected, very few questions were asked on Facebook probably due to students' shyness which prevent them to ask questions in a public setting. ${ }^{10}$

Moreover, the expected emulation between students did not take place. This lack of interactions between students (visible by the teacher, see questionnaire Table 1) is probably also due to the lack of preparation for distance learning and a lack of incentive on the teacher's part to interact via the social network.

From the teacher's point of view, the solution presented seems to be very appropriate in this time of uncertainty and disruption. Nevertheless, in order to assess the students' feelings during this period of distance learning, a questionnaire (Table 1) was set up. The questionnaire takes the form of a series of statements with which students are asked to give their level of agreement or disagreement.

Thus, of the 22 students who made the effort to register on the private Facebook group to access the video content, 20 responded to the questionnaire and the responses have been compiled below.

Table 1. Distribution of Students' Responses to the Questionnaire $(N=20)$ in percentage






\begin{tabular}{|c|c|c|c|c|c|c|}
\hline 6 & Using Facebook as a platform for exchange is a good idea. & 50 & 45 & 5 & 0 & 0 \\
\hline 7 & $\begin{array}{l}\text { The use of videos to explain exercises solutions is more } \\
\text { suitable than real-time (synchronous) explanation via a } \\
\text { platform like Discord. }\end{array}$ & 60 & 35 & 5 & 0 & 0 \\
\hline 8 & $\begin{array}{l}\text { The use of video requires more work than live exercises } \\
\text { explanation via Discord. }\end{array}$ & 0 & 15 & 10 & 45 & 30 \\
\hline 9 & $\begin{array}{l}\text { The use of videos to explain exercises solutions is more } \\
\text { suitable than face-to-face explanation in a classroom. }\end{array}$ & 0 & 5 & 20 & 60 & 15 \\
\hline 10 & With videos, the teacher is no longer indispensable. & 0 & 0 & 5 & 30 & 65 \\
\hline 11 & $\begin{array}{l}\text { The } 24 / 7 \text { access to videos helped you during this learning } \\
\text { period. }\end{array}$ & 65 & 30 & 5 & 0 & 0 \\
\hline 12 & $\begin{array}{l}\text { Being able to watch the videos several times is an asset for } \\
\text { understanding. }\end{array}$ & 80 & 20 & 0 & 0 & 0 \\
\hline 13 & $\begin{array}{l}\text { During these organic chemistry tutorials, the students } \\
\text { helped each other. }\end{array}$ & 10 & 55 & 30 & 0 & 5 \\
\hline 14 & $\begin{array}{l}\text { The use of videos for organic chemistry tutorials must } \\
\text { continue beyond lockdown. }\end{array}$ & 40 & 35 & 15 & 5 & 5 \\
\hline
\end{tabular}

\section{DISCUSSION}

The first finding of this questionnaire is that students are rather worried about the continuation of their studies (only 10\% disagree with statement 1) and they find that the modalities of distance examinations (entry 2) are uneven, particularly with regard to the computer equipment available and the conditions of concentration. Moreover, it seems that in the interest of pedagogical continuity, teachers have increased their workload (entry 3). This feeling can also be explained by the active learning character of distance education compared to a certain passivity on the part of the student during transmissive teaching. In order to help with workload distribution, a schedule was provided to students to enable them to identify fixed times to work on a dedicated subject. Indeed, as a teacher, it is important to measure the overall workload of the student and not only that of the course being taught. The use of this schedule is very important to guide students (entry 4). When comparing fully synchronous distance learning with the presented approach employing videos, 95\% of the students think that the use of videos is more suitable for exercises solutions explanation (entry 7) without requiring more effort than for live explanation. The students underline $(75 \%)$ that traditional classroom teaching is nevertheless more suitable (entry 9) and agree that the presence of the teacher remains indispensable (entry 10). Students also agree on the benefits of asynchronous videos which are the possibility of watching videos multiple times at any time (entries 11 and 12). This advantage is extremely interesting because it allows students to perform the exercises at their own pace without 
being pressed by a constrained hourly volume that may cause them to stall and give up. It also represents a challenge for the teacher who has to successively answer questions on different exercises/notions in order to make each individual in the group progress. Surprisingly, more than half of the students said that there was mutual help between students (entry 13). On the teacher's side a lack of interaction was observed as discussed above. Unfortunately, some students stayed isolated during the whole period. The last point (entry 14) about the perpetuation of videos in normal times raises the question of the evolution of traditional teaching toward hybrid teaching.

\section{CONCLUSION}

In conclusion, it was presented a simple way to teach organic chemistry tutorials during a time of disruption. This approach, combining synchronous and asynchronous teaching, consists in proposing to the students videos accessible $24 / 7$ on Facebook as well as moments of live exchanges on the Discord platform. The major lessons of this experience of teaching during a lockdown are i) asynchronous teaching is preferable to real-time teaching for exercises solutions explanations ii) videos allow students to progress at their own pace with the ability to watch videos several times at any time iii) students need a framework (timetable) to help them organize themselves to manage their workload. The distance teaching approach during disruption is not intended to completely replace classroom teaching, but it opens up new perspectives to complement it.

\section{AUTHOR INFORMATION}

Corresponding Author

*E-mail: danjou@univ-littoral.fr

\section{ACKNOWLEDGMENTS}

Rachel Stévenin is warmly acknowledged for fruitful discussion about teaching during lockdown. Thanks to Thomas and Martin for giving me time to prepare this manuscript. I would also like to thank the first-year undergraduate students of Physics and Chemistry (promotion 2019-2020) at the Université du Littoral Côte d'Opale for their kindness during this period and for agreeing to answer the questionnaire. 


\section{REFERENCES}

(1) Discord Home Page. https://discord.com/ (accessed May 10, 2020).

(2) Pienta, N. J. Introductory Chemistry Using the "Flipped" Environment: An Update. J. Chem. Educ. 2019, 96 (6), 1053-1054. https://doi.org/10.1021/acs.jchemed.9b00458.

(3) Bokosmaty, R.; Bridgeman, A.; Muir, M. Using a Partially Flipped Learning Model To Teach First Year Undergraduate Chemistry. J. Chem. Educ. 2019, 96 (4), 629-639. https://doi.org/10.1021/acs.jchemed.8b00414.

(4) Rossi, R. D. ConfChem Conference on Flipped Classroom: Improving Student Engagement in Organic Chemistry Using the Inverted Classroom Model. J. Chem. Educ. 2015, 92 (9), 1577-1579. https://doi.org/10.1021/ed500899e.

(5) Alden, E. ConfChem Conference on Select 2016 BCCE Presentations: Changing Roles for Changing Times-Social Media and the Evolution of the Supplemental Instructor. J. Chem. Educ. 2017, 94 (12), 2007-2009. https://doi.org/10.1021/acs.jchemed.6b01012.

(6) Rose, J.; Pennington, R.; Behmke, D.; Kerven, D.; Lutz, R.; Paredes, J. E. B. Maximizing Student Engagement Outside the Classroom with Organic Synthesis Videos. J. Chem. Educ. 2019, 96 (11), 2632-2637. https://doi.org/10.1021/acs.jchemed.9b00234.

(7) Rau, M. A.; Kennedy, K.; Oxtoby, L.; Bollom, M.; Moore, J. W. Unpacking “Active Learning”: A Combination of Flipped Classroom and Collaboration Support Is More Effective but Collaboration Support Alone Is Not. J. Chem. Educ. 2017, 94 (10), 1406-1414. https://doi.org/10.1021/acs.jchemed.7b00240.

(8) Fung, F. M. Adopting Lightboard for a Chemistry Flipped Classroom To Improve TechnologyEnhanced Videos for Better Learner Engagement. J. Chem. Educ. 2017, 94 (7), 956-959. https://doi.org/10.1021/acs.jchemed.7b00004.

(9) Khan Academy Home Page. https://www.khanacademy.org/science/organic-chemistry (accessed May 10, 2020).

(10) Fautch, J. M. The Flipped Classroom for Teaching Organic Chemistry in Small Classes: Is It Effective? Chem. Educ. Res. Pract. 2015, 16 (1), 179-186. https://doi.org/10.1039/C4RP00230J. 